\title{
Rapid reporting on fine needle aspiration of breast lumps in outpatients
}

\author{
J A ZUK, GILLIAN MAUDSLEY, H D ZAKHOUR
}

From the Department of Histopathology, Arrowe Park Hospital, Upton, Wirral, Merseyside

SUMMARY A retrospective analysis of the performance and value of fine needle aspiration of symptomatic breast masses in a special outpatient "breast clinic" within a district general hospital was carried out. All but a few aspirations were performed by a group of histopathologists, with, immediate cytological reporting. Fine needle aspiration was more sensitive for detecting malignancy than clinical assessment alone, the sensitivity increasing with the experience of the aspirator. The results compared favourably with those in reported series from specialist centres in the United Kingdom.

The value of fine needle aspiration extends to the overall management of patients with breast masses but the results must be assessed in conjunction with the clinical context in view of the possibility of false negative or, more rarely, false positive cytological diagnoses.

The role of fine needle aspiration in the management of women with symptomatic breast masses has been well established for many years in certain European countries $^{1-3}$ and in the United States of America. ${ }^{4-7}$ It has not been until relatively recently that fine needle aspiration has begun to be accepted in the United Kingdom. ${ }^{8}$

Published results of most British series have originated in centres which are either university departments of surgery and histopathology/cytology, ${ }^{9-11}$ or where a specialist cytopathologist is responsible for cytological interpretation. ${ }^{1213}$ In these British studies the aspiration procedure was performed by the examining clinician and the aspirate interpreted by a pathologist, either at the clinic with immediate reporting, ${ }^{112}$ or back at the laboratory.

We present a statistical analysis of fine needle aspiration cytology of breast masses, mostly performed by a group of histopathologists with immediate cytological reporting. The purpose of the study was to assess the value of the procedure in a specialist breast lump clinic in a district general hospital.

\section{Material and methods}

In July 1986 a joint weekly breast clinic, run by one surgical team and a group of histopathologists (ultimately three), was established at this hospital.

Accepted for publication 31 March 1989
Patients with symptomatic breast masses are referred directly by the general practitioner to this clinic, and after initial assessment by a surgeon, a large proportion undergo immediate fine needle aspiration by the participating histopathologist, and occasionally by the surgeon himself if the mass is deemed to be cystic. Aspirates are obtained by a standard, well described, technique $^{l}$ and, if from a solid mass, the content is smeared directly on to glass slides, air dried, and stained with Diff-Quick (Merz and Dade, Switzerland) at the clinic. Alternatively, if the mass is a cyst the fluid content is transferred to the laboratory and stained by May-Grünwald-Giemsa and Papanicolaou techniques after cytocentrifugation, but the cyst wall is aspirated and treated like a solid mass. All aspirates from solid lesions are reported within about 20 minutes of the procedure; those from cysts are necessarily delayed because they are processed at a later time in the laboratory.

CATEGORIES OF ASPIRATE

All aspirates are classified into the following groups: Inadequate: either extremely hypocellular with regard to epithelial cells or bloodstained to an extent that all other elements are obscured.

Benign: characterised by sheets of regular ductal cells with nuclear features of benign cells, often admixed with a large number of "stripped" nuclei.

Suspicious: hypercellular specimen which has an admixture of regular cells and others with abnormal nuclear and cytoplasmic features falling short of a firm 
diagnosis of malignancy.

Malignant: hypercellular specimen comprising cells with unequivocal cytological features of malignancy.

If an aspirate was initially classified as inadequate, the procedure was repeated.

\section{STUDY POPULATION}

A total of 180 patients underwent fine needle aspiration during the first nine months of this clinic's operation. Case reports were available from 174 patients, three of whom were excluded from the study: one had a basal cell carcinoma of skin and two presented with masses in previous mastectomy scars. The clinicopathological data retrieved included age, sex, site of lesion(s), clinical impression before aspiration, aspirate category, surgical procedure(s), histological analysis and follow up.

\section{STATISTICAL ANALYSIS}

Standard statistical evaluation was performed, as previously described, ${ }^{14}$ on aspirates of all solid lesions. The absolute sensitivity was the fraction of all patients with malignancy in whom the fine needle aspirate was unequivocally malignant; complete sensitivity was the fraction of all patients with malignancy in whom the aspirate was suspicious or malignant. The false negative rate was the fraction of malignant lesions for which fine needle aspiration failed to indicate any abnormality; specificity was the fraction of cases of benign breast disease in which the aspirate was unequivocally benign. The predictive value of a malignant diagnosis was the fraction of all unequivocally malignant aspirates that were malignant histologically, or were clinically obvious malignancies, being locally advanced fungating tumours. The false positive rate was $100 \%$ minus the predictive value of a malignant diagnosis; the predictive value of a benign diagnosis was the fraction of all benign aspirates confirmed as benign histologically, or deemed to be benign on follow up at the clinic or by the referring general practitioner.

\section{Results}

During the nine months of study, a total of 187 aspirates were performed on 171 patients (14 had two and one had three aspirates). Average age was $45 \cdot 6$ years (range 19-83) and one patient was male. Only 17 had had mammography. The anatomical distribution of the lesions aspirated is shown in the figure. Fifty five percent of aspirates were from the left and $45 \%$ from the right breast. The clinical impression of the masses, as determined by the surgeon before aspiration, is shown in table 1. During aspiration, a total of 49 lesions $(26 \%)$ were confirmed to be cystic, 32 having been performed by surgeons and 17 by pathologists.

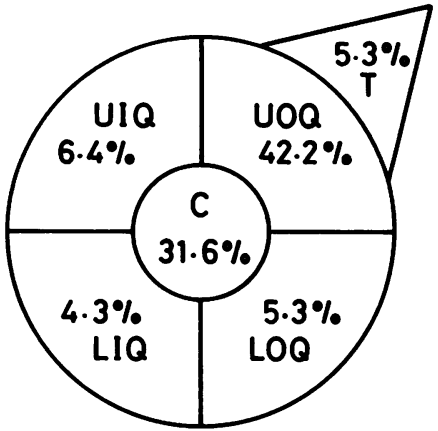

Whole breast $0.5 \%$ Not stated $\quad 4.3 \%$

UOQ $=$ Upper outer quadrant $L O Q=$ Lower outer quadrant $L I Q=$ Lower inner quadrant UIQ $=$ Upper inner quadrant $\mathrm{C}=$ Central

$T=$ Axillary tail

Clinical examination, therefore, overestimates the true proportion of masses assessed as cystic. Two of the 15 lesions that were clinically cystic, but solid on aspiration, were malignant on histological examination, one of these having been correctly characterised by fine needle aspiration. The proportion of solid lesions $(n=137)$ aspirated by each individual pathologist, or by a surgeon, is shown in table 2. Pathologist III (who performed the least number of aspirations) only participated during the final three months of the study.

It is with this group of 137 solid lesions (on aspiration) that the rest of the analysis is concerned. Thirty two were histologically confirmed malignancies of the following type: infiltrating ductal carcinomas $(n=28)$; infiltrating lobular carcinomas $(n=3)$; and angiosarcoma $(n=1)$. A further two masses were clinically obvious carcinomas, being locally advanced, fungating tumours (both malignant on aspiration). In benign breast disease 55 lesions were histologically assessed the remaining 48 being designated as benign on clinical grounds at follow up for an average six months (range 0-21 months) at the clinic, followed by individual monitoring by the general practitioner.

Table 1 Clinical impression of mass before fine needle aspiration

\begin{tabular}{lc}
\hline Clinical category & Percentage of masses \\
\hline Benign, cyst & $31 \cdot 5$ \\
Benign, diffusely nodular & $22 \cdot 5$ \\
Benign, single solid mass & $29 \cdot 4$ \\
Suspicious (of carcinoma) & 7 \\
Malignant & $9 \cdot 1$ \\
Not stated & $0 \cdot 5$ \\
\hline
\end{tabular}


Table 2 Proportion of solid lesions $(n=137)$ aspirated by each pathologist, including inadequate rate

\begin{tabular}{|c|c|c|}
\hline Aspirator & $\begin{array}{l}\text { Number } \\
\text { (\% of total) } \\
\text { of solid } \\
\text { lesions aspirated }\end{array}$ & $\begin{array}{l}\text { Number (\%) of } \\
\text { inadequate aspirates }\end{array}$ \\
\hline $\begin{array}{l}\text { Pathologist I } \\
\text { Pathologist II } \\
\text { Pathologist III } \\
\text { Surgeon } \\
\text { Total }\end{array}$ & $\begin{array}{rr}70 & (51 \cdot 1) \\
50 & (36 \cdot 5) \\
15 & (10 \cdot 9) \\
2 & (1 \cdot 5) \\
137 & \end{array}$ & $\begin{array}{cc}2 & (3) \\
7 & (14) \\
5 & (33) \\
14 & \end{array}$ \\
\hline
\end{tabular}

STATISTICAL ANALYSIS OF PERFORMANCE OF ASPIRATION OF SOLID LESIONS $(\mathbf{n}=137)$

The standard evaluation of performance of fine needle aspiration ${ }^{14}$ was assessed for the group of aspirators as a whole, and compared with values obtained for pathologist I, who performed most (70) aspirates (table 3). Standard analysis was also applied to the clinical assessment before aspiration. The pathologist with most aspiration experience had superior results for sensitivity of detection of malignancy compared with the group of aspirators as a whole.

A large proportion of the difference in these results can be explained by differences in the proportion of inadequate aspirates obtained. Pathologist I had no inadequate aspirates from malignancies; the group as a whole had five. If these five cases were to be deleted from calculations, the values achieved for absolute and complete sensitivity for malignancy for the whole group would be $69 \%$ and $83 \%$, respectively. Likewise, this would lead to a reduction in false negative rate to $17 \%$. The calculated values of specificity and predictive values of malignant and benign diagnoses for both groups were similar (table 3 ). Only one false positive fine needle aspiration diagnosis of malignancy was made.

Clinical assessment alone, compared with the

Table 3 Statistical analysis of fine needle aspiration (for whole group and for pathologist I) comparison with clinical assessment of solid masses ( $n=137)$

\begin{tabular}{|c|c|c|c|}
\hline \multirow[b]{2}{*}{ Test value } & \multicolumn{2}{|c|}{ Fine needle aspiration } & \multirow[b]{2}{*}{$\begin{array}{l}\text { Clinical } \\
\text { assessment }\end{array}$} \\
\hline & $\begin{array}{l}\text { Whole } \\
\text { group }\end{array}$ & $\begin{array}{l}\text { Pathologist } \\
\text { I }\end{array}$ & \\
\hline \multirow{4}{*}{$\begin{array}{l}\text { Absolute sensitivity } \\
\text { for malignancy } \\
\text { Complete sensitivity } \\
\text { for malignancy } \\
\text { False negative rate } \\
\text { Specificity } \\
\text { Predictive value of } \\
\text { malignant diagnosis } \\
\text { False positive rate } \\
\text { Predictive value of } \\
\text { benign diagnosis }\end{array}$} & $58 \cdot 8$ & $87 \cdot 5$ & 50 \\
\hline & $\begin{array}{l}70 \cdot 6 \\
29 \cdot 4 \\
87 \cdot 5\end{array}$ & $\begin{array}{l}87.5 \\
12.5 \\
90 \cdot 7\end{array}$ & $\begin{array}{l}73 \cdot 5 \\
26 \cdot 5 \\
96 \cdot 1\end{array}$ \\
\hline & $\begin{array}{r}95 \cdot 2 \\
4.8\end{array}$ & $\begin{array}{r}93.3 \\
6.7\end{array}$ & $\begin{array}{l}100 \\
\text { Nil }\end{array}$ \\
\hline & $94 \cdot 7$ & $96 \cdot 1$ & 92.5 \\
\hline
\end{tabular}

results of the most experienced aspirator (pathologist I) in particular, was less sensitive than fine needle aspiration in detecting malignancy, but the predictive value of a malignant clinical diagnosis was $100 \%$ that is, the total yield of malignancies diagnosed by aspiration was greater than that obtained by clinical assessment alone, and this increased with experience.

CORRELATION BETWEEN CLINICAL IMPRESSION, ASPIRATION REPORT AND HISTOLOGICAL

DIAGNOSIS (table 4)

Histological analysis was done on 87 solid breast lesions. Table 4 evaluates the contribution made by fine needle aspiration in the management of the clinically suspicious breast mass. Interestingly, when there was clinical suspicion of malignancy (10 cases), and as long as the aspirate was of adequate quality $(n=8)$, it was useful, in that all five cases assessed cytologically as either malignant or suspicious were indeed malignant histologically; only one out of three assessed as benign on aspiration was falsely negative.

\section{ANAL YSIS OF INADEQUATE ASPIRATES}

Even after repeating the procedure as required, the fine needle aspirate remained inadequate in 14 out of the total of 137 solid breast lesions. All 14 had histological diagnoses. There was a positive correlation between experience of aspirator and proportion of inadequate aspirates (table 3 ). The sizeo of malignancy (as determined from histology) was also? associated with the inadequacy of aspirate obtained (table 5). In our series, average size of malignancy was $2.95 \mathrm{~cm}$ (range $1.0-7.0 \mathrm{~cm}$ ). Those less than $2 \mathrm{~cm}$ in maximum dimension had an inadequate aspiration rate of $37.5 \%$ with a similar proportion wrongly categorised as benign on fine needle aspiration. There was no relation between site of lesion, type of malignancy, age of patient and adequacy of aspirate.

\section{ANAL YSIS OF FROZEN SECTIONS (table 6)}

On 23 masses (where a clinical impression was given) intraoperative urgent frozen section examination was performed (all subsequently verified as correct on paraffin wax sectioning). Table 6 shows the association between initial clinical impression (preoperatively), result of fine needle aspiration, and ultimate histological diagnosis in these cases. The effect of preoperative fine needle aspiration on the frozen section rate was difficult to ascertain, as factors other than preoperative assessment determine the need for this. For example, seven out of 15 clinically benign masses, despite having an adequate benign fine needle aspirate, still had urgent frozen section (six histologically benign, one malignant). Only one of this group of seven had had mammography (suspicious) and it was concluded that, in many of these cases, 
Table 4 Comparison of clinical impression, aspirate report, and final histological diagnosis $(n=87)^{*}$

\begin{tabular}{|c|c|c|c|c|}
\hline & $\begin{array}{l}\text { Fine needle } \\
\text { aspirate }\end{array}$ & $\begin{array}{l}\text { Fine needle } \\
\text { aspirate }\end{array}$ & $\begin{array}{l}\text { Fine needle } \\
\text { aspirate }\end{array}$ & $\begin{array}{l}\text { Fine needle } \\
\text { aspirate }\end{array}$ \\
\hline $\begin{array}{l}\text { Clinical } \\
\text { impression }\end{array}$ & Benign $<_{\text {Malignant }}^{\text {Benign }}$ & Suspicious $<_{\text {Malignant }}^{\text {Benign }}$ & Malignant $<_{\text {Malignant }}^{\text {Benign }}$ & Inadequate $<_{\text {Malignant }}^{\text {Benign }}$ \\
\hline Benign $(n=61)$ & $44<^{40}$ & $3 \leftarrow^{3}$ & $3 \leftarrow^{1}$ & $11<^{9}$ \\
\hline Suspicious $(\mathrm{n}=10)$ & $3 \leftarrow^{2}$ & $2 \longleftarrow^{0}$ & $3 \leftarrow^{0}$ & $2 \leftarrow$ \\
\hline Malignant $(n=15)$ & 0 & $1 \varlimsup^{0}$ & $13 \leftarrow$ & $1<$ \\
\hline
\end{tabular}

*One case - No clinical impression.

Table 5 Correlation between size of malignancy and aspirate result

\begin{tabular}{llllll}
\hline $\begin{array}{l}\text { Size of } \\
\text { malignancy in } \\
\begin{array}{l}\text { (number in } \\
\text { range) }\end{array}\end{array}$ & Aspirate category \\
\cline { 2 - 6 } & Inadequate & Benign & Suspicious & Malignant \\
\hline $1 \leqslant 2$ & $(8)$ & 3 & 3 & 1 & 1 \\
$2 \leqslant 3$ & $(11)$ & 1 & - & 1 & 9 \\
$3 \leqslant 4$ & $(5)$ & 1 & - & 1 & 3 \\
$>4$ & $(8)$ & - & 2 & 1 & 5 \\
$n=32$ & 5 & 5 & 5 & 4 & 18 \\
\hline
\end{tabular}

intraoperative assessment was important for determining the need for frozen section.

We had only one false positive fine needle aspirate. This mass had an urgent frozen section, the result of which was deferred until paraffin wax sections were available. These showed only florid adenosis.

\section{Discussion}

Published reports show that physical examination, followed by fine needle aspiration with immediate cytological reporting, seems to be unique for this country, ${ }^{10-1215}$ but that this is standard practice in certain European centres. ${ }^{1}$ There are advantages if the pathologist performs the aspirate because extra, potentially diagnostic information contributing to smear interpretation is gained from palpation and from the feel of the needle traversing the mass." Inadequate preparations, and those inconsistent with the clinical picture, can be repeated if cytological assessment is immediate, and appropriate patient management can be discussed with the surgeon.

Although relatively small, our analysis concerned an almost complete study population $(97 \%)$ and had a long follow up. In absolute statistical terms more malignancies were detected by fine needle aspiration

Table 6 Clinical impression, aspirate category, and frozen section results

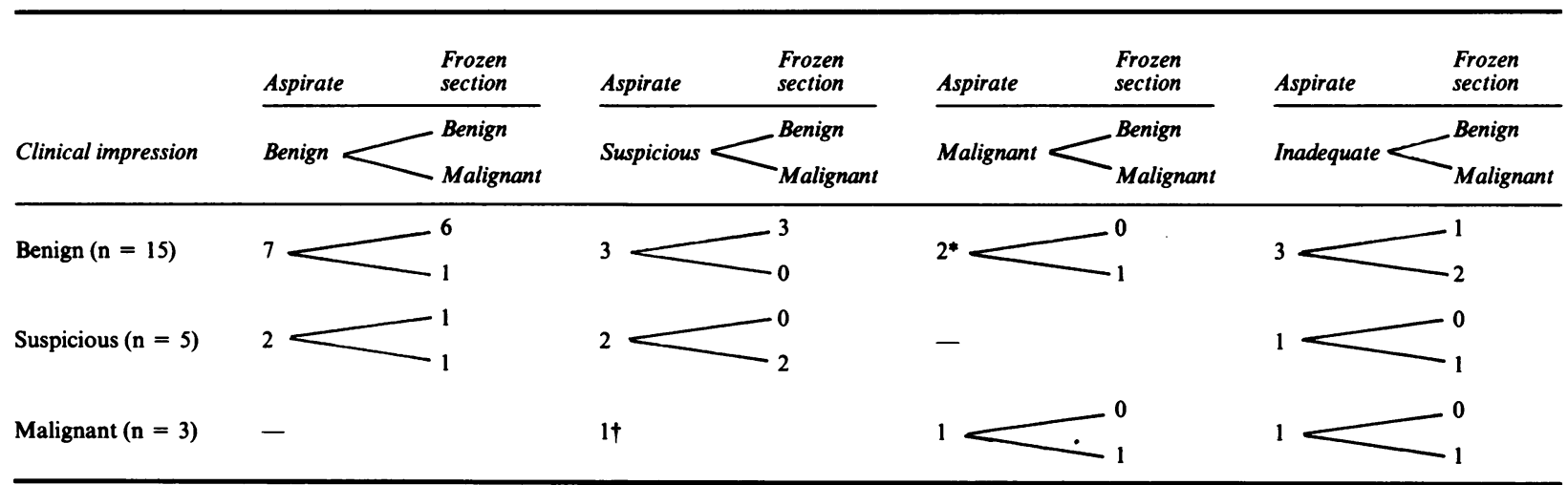

*One of these two cases-await paraffin wax sections (final diagnosis-adenosis).

†Await paraffin wax sections-final diagnosis angiosarcoma. 
than by clinical examination alone, and this was particularly true the more experienced the aspirator: the most experienced aspirator had values for absolute and complete sensitivity for malignancy of $87.5 \%$. Figures from other series for absolute sensitivity vary from $52 \%$ to $95 \%^{124515}$ and complete sensitivity for malignancy from $80 \%$ to $95 \%{ }^{14579}$ which show that our results were favourable. Occasional published results of performance are based on calculations which exclude inadequate aspirates. ${ }^{11}$ After such exclusion the values obtained for our group of aspirators as a whole, for absolute and complete sensitivity for malignancy, would be $69 \%$ and $83 \%$, respectively.

Other studies have also found that fine needle aspiration detects more malignancies than clinical examination with or without mammography. ${ }^{61012}$ Gardecki et al also reached this conclusion but emphasised that the aspirate must be of adequate quality. ${ }^{13}$ In our study any analysis concerning mammography was impossible as only 17 patients had had this investigation. We found a clinical overestimation of benign breast disease of $5 \%$ (eight out of 156 cases), a figure identical with that found by Duguid et al..$^{12}$ In two of these eight cases the aspirate proved malignant. We also found that fine needle aspiration helped to arrive at the correct diagnosis in clinically suspicious breast masses in most cases (table 4).

Of obvious concern with any investigative procedure are false negative results. For our most experienced aspirator this was $12 \cdot 5 \%$, but for the group as a whole, it was $\mathbf{2 9 \cdot 4} \%$. Published figures range from $4 \%$ to $48 \% .^{1341115}$ In our study the principal reason for the high false negative rate for the group as a whole was due to inadequate quality of aspirates, despite the procedure being repeated if required. We found the rate of inadequacy to depend largely on the individual aspirator (table 2) as found in other studies. ${ }^{410}$ This depends on individual technique $^{1117}$ as well as on overall experience. A further area of possible variability concerns interobserver assessment in the subjective analysis of the aspirate itself, this being readily understandable in the situation of immediate reporting.

Other factors which have also been reported to be of importance in detecting malignancies concern tumour type, with one study ${ }^{5}$ detecting only $25 \%$ of lobular carcinoma compared with $69 \%$ of ductal carcinomas. Our study had too few lobular carcinomas to reach conclusions confidently, but no obvious association was apparent. The false negative rate in malignancy also depends on tumour size, with small ${ }^{351318}$ or, indeed, very large ${ }^{3}$ tumours having lower rates of positive cytological detection. We found high inadequate and false negative rates for malignancies less than $2 \mathrm{~cm}$ in maximum diameter (table 5).
Tumour size is of obvious importance when considering fine needle aspiration in screening for breast carcinoma in asymptomatic women. ${ }^{18}$ Further reported reasons for inadequacy or false negative results in malignancy include age of patient, ${ }^{9}$ tumour differentiation, ${ }^{319}$ and the presence of deep seated lesions, especially in patients with pendulous breasts. ${ }^{13}$

Perhaps one of the most important areas of concern are false positive results. Only one of our aspirates was falsely diagnosed as malignant cytologically. Several published series also include false positive diagnoses, ranging from $1 \%$ to $4 \%$ of all aspirates performed. ${ }^{271115}$ Even in studies of several thousand aspirates, performed by vastly experienced doctors, ${ }^{13}$ false positive results have been found. What is important is how surgical treatment is influenced in these cases. In our case the mass was subjected to lumpectomy alone with intraoperative urgent frozen section. We emphasise that the usefulness of fine needle aspiration of breast is probably more relevant in terms of the overall contribution to preoperative assessment of individual patients, a conclusion similarly reached by others, ${ }^{8111220}$ and special care is needed in cases with any clinicopathological discordance, as with any investigative technique.

The effect of preoperative fine needle aspiration on the number of frozen sections required has been difficult to evaluate in our study. Previous reports indicate a variety of findings and views, with one studyoc claiming an $80 \%$ reduction. ${ }^{13}$ Most conclude that the procedure does not replace frozen section analysis. In our view the procedure should substantially reduce the need for frozen section, particularly in cases where the fine needle aspiration assessment is in total agreement with the clinical impression.

As well as advantages to the surgeon from preoperative assessment, the procedure obviates the need for formal biopsy in those with locally advanced disease before radiotherapy or chemotherapy. The aspiration procedure itself is safe $\mathrm{s}^{21}$ and well tolerated, with psychological benefits for the patient where immediate reporting is undertaken, as in our clinical set up. It must be emphasised, however, that information conveyed to the patient as to the nature of the lesion should be given with caution where there is clinicopathological disparity, in view of the possibility of false negative or false positive results.

Acknowledgements are due to Mr J Shennan (consultant surgeon) for allowing us to publish information concerning his patients, and to Drs AH Clark and MB Gillett for allowing us to analyse their fine needle aspirates. Thanks are due to Miss J Smith, who typed the manuscript. 
References

1 Franzén S, Zajicek J. Aspiration biopsy in the diagnosis of palpable lesions of the breast. Acta Radiol 1968;7:241-62.

2 Stavrić GD, Tevčev DT, Kaftandjiev DR, Novak JJ. Aspiration biopsy cytologic method in diagnosis of breast lesions. A critical review of 250 cases. Acta Cytol 1973;17:188-90.

3 Zajdela A, Ghossein NA, Pilleron JP, Ennuyer A. The value of aspiration cytology in the diagnosis of breast cancer: experience at the Curie Foundation. Cancer 1975;35:499-506.

4 Abele JS, Miller TR, Goodson WH, Hunt TK, Hohn DC. Fineneedle aspiration of palpable breast masses. Arch Surg 1983; 118:859-63.

5 Eisenberg AJ, Hajdu SI, Wilhelmus J, Melamed MR, Kinne D. Pre-operative aspiration cytology of breast tumors. Acta Cytol 1986;30:135-46.

6 Bell DA, Hajdu SI, Urban JA, Gaston JP. Role of aspiration cytology in the diagnosis and management of mammary lesions in office practice. Cancer 1983;51:1182-9.

7 Kline TS, Joshi LP, Neal HS. Fine needle aspiration of the breast: diagnoses and pit falls. A review of 3,545 cases. Cancer 1979; 44:1458-64.

8 Lever JV, Trott PA, Webb AJ. Fine needle aspiration cytology. J Clin Pathol 1985;38:1-11.

9 Barrows GH, Anderson TJ, Lamb JL, Dixon JM. Fine-needle aspiration of breast cancer. Relationship of clinical factors to cytology results in 689 primary malignancies. Cancer 1986;58 1493-8.

10 Dixon JM, Anderson TJ, Lamb J, Nixon S'J, Forrest APM. Fine needle aspiration cytology, in relationship to clinical examination and mammography in the diagnosis of a solid breast mass. Br J Surg 1984;71:593-6.

11 Furnival CM, Hughes HE, Hocking MA, Reid MMW, Blumgart LH. Aspiration cytology in breast cancer. Its relevance to diagnosis. Lancet 1975;ii:446-8.
12 Duguid HLD, Wood RAB, Irving AD, Preece PE, Cuschieri A. Needle aspiration of the breast with immediate reporting. $\mathrm{Br}$ Med J 1979;ii: 185-7.

13 Gardecki TIM, Hogbin BM, Melcher DH, Smith RS. Aspiration cytology in the pre-operative management of breast cancer. Lancet 1980;ii:790-2.

14 Galen R, Gambino SR. Beyond normality: the predictive value and efficiency of medical diagnosis. New York: John Wiley and Sons Inc, 1975:10-14.

15 Elston CW, Cotton RE, Davies CJ, Blamey RW. A comparison of the use of "Tru-cut" needle and fine needle aspiration cytology in the pre-operative diagnosis of carcinoma of the breast. Histopathology 1978;2:239-54.

16 Painter RW, Clark WE, Deckers PJ. Negative findings on fine needle aspiration biopsy of solid breast masses: patient management. Am J Surg 1988;155:387-90.

17 Hartley MN, Tuffnell DJ, Hutton JL, Palmer M, Al-Jafari MS. Fine needle aspiration cytology: an in vitro study of cell yield. $\mathrm{Br}$ J Surg 1988;75:380-1.

18 Lamb J, Anderson TJ, Dixon MJ, Levack PA. Role of fine needle aspiration cytology in breast cancer screening. $J$ Clin Pathol 1987;40:705-9.

19 Thomas J St J, Mallon EA, George WD. Semiquantitative analyses of fine needle aspirates from benign and malignant breast lesions. J Clin Pathol 1989;42:28-34.

20 Anonymous. Utility of needle aspiration of tumours [Editorial]. $\mathrm{Br}$ Med J 1978;i:1507-8.

21 Berg JW, Robbins GF. A late look at the safety of aspiration biopsy. Cancer 1962;15:826-7.

Requests for reprints to: Dr H D Zakhour, Department of Histopathology, Arrowe Park Hospital, Arrowe Park Road, Upton, Wirral L49 5PE, England. 